\title{
OPEN
}

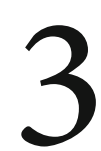

\section{The Impossible Constellation: Practice as Research as a Viable Alternative ${ }^{1}$}

\section{Sarah Barrow}

\begin{abstract}
This chapter draws attention to the features, values and debates of Practice as Research, arguing for its approaches, methods and outputs to be considered as equivalent to those used by more traditional humanities scholars, i.e. the 'academic book'. Indeed, it asks us to rethink our fetishisation of the physical book artefact as the pre-eminent model of publication in academic terms, and suggests we explore and support the development of other forms that might be more relevant to the digital age, and that attempt to break down the walls between theory and practice. It ends with a focus on the video essay form, which has the potential to reshape the subjects of Media and Film Studies in particular.
\end{abstract}

Keywords: fetishisation of text; non-textual research outputs; Practice as Research; theory and practice; video essay

Lyons, Rebecca E. and Samantha J. Rayner (eds). The Academic Book of the Future. Basingstoke: Palgrave Macmillan, 2016. DOI: 10.1057/9781137595775.0008. 
The difficulty with the term 'academic book' for those working in creative arts subjects, whether critical studies or creative production, or a fruitful combination of both these areas, is that the very word 'book' conjures up almost exclusively the image of a physical set of written, printed, illustrated sheets, made of ink, paper, parchment, or other materials, and fastened together at one side. And yet in an age of technical innovation, when we are encouraged by funders, institutions, our students and our own imaginations to think and work more creatively and to explore across traditional disciplinary boundaries, it is time to normalise alternative ways to publish and circulate ideas. This statement is not an attempt to undermine the enormous value of the physical 'book' or the rigour and review that goes with its publication; rather it is to do with seeking acknowledgement for and trust in alternative ways of doing and presenting research, valorising interdisciplinary and collaborative effort, and accepting that high-quality academic endeavour might result in something 'other'.

This brief essay highlights an approach to research and publication that has become increasingly important within the creative arts, and yet which still seems to be treated with scepticism by those more comfortable with traditional formats. This approach, most commonly known as 'Practice as Research' [PaR] has been much debated and scrutinised over the last two decades in particular, with a burgeoning literature, specialist subject networks, funded investigations in the UK and elsewhere, and a host of events that have attempted to gather together so-called traditional scholars with practitioner researchers to test the boundaries of acceptable research approaches and publication formats. ${ }^{2}$ Since this approach emerged as a result of the establishment of positions, programmes, departments, and even universities of and for the arts when previously artist-scholars and art schools were regarded as separate entities, it has become necessary and desirable for distinctions to be identified between 'Practice as Research' and professional practice (whether from artistic or industry contexts) where the research element is not so vital. For Denis Nelson, for example, 'PaR involves a research project in which practice is a key method of inquiry and where, in respect of the arts, a practice (creative writing, dance, musical score/ performance, theatre/performance, visual exhibition, film, or other cultural practice) is submitted as substantial evidence of a research inquiry.' ${ }^{3}$ It is a kind of 'practical knowing-in-doing', where insight, methodological rigour and originality are key, and might be shared 
with and learn from other practice-based disciplines such as education and ethnography.

This issue for media subjects in particular in terms of the pre-eminent privileging of 'the book' was brought to the fore yet again in the most recent Research Excellence Framework 2014, when the sub-panel for Unit of Assessment 36 (Communication, Cultural and Media Studies, Library and Information Management) ${ }^{4}$ failed to include a single practitioner-researcher. ${ }^{5}$ This led to understandable anxiety amongst some academics (or their institutions) when it came to making the key decisions about which of their outputs to propose for submission. Many decided to play it safe and stick with the traditional output formats even when some of their most complex, rigorous and original work - with the most impact potential - had been produced in a media format: video, script, installation, sonic art, multimedia platform, for example. It is not just academic institutions that have been hesitant to support the Practice as Research approach, despite the possibility of embracing a more inclusive agenda in so doing. Within the media subjects, many professional practitioners-turned-academics from a more emphatically industrial background tend to resist the need to make explicit the specific research elements of their creative endeavour, viewing it as 'an unwarranted imposition from beyond their culture. ${ }^{6}$ Meanwhile, more established scholars in media with backgrounds in the humanities/social sciences have struggled to appreciate Practice as Research as a viable approach for subject areas that are still fighting to be taken seriously by the academy as disciplines in themselves. And yet, with increasing economic pressures, the need for practitioners, as Sullivan has put it, 'to consider their responsibilities as researchers as well as teachers' has become impossible to ignore and in fact has the potential to force institutional structures to open up in response to a new mood of innovation and change.?

One PaR approach to enquiry and output that has long been familiar within the world of experimental media, and seems to be making a resurgence as a serious player on the research and publication agenda is the video essay/essay film. The term was used as far back as the 1940s by abstract Dadaist German film-maker Hans Richter, as a form that 'allows the film-maker to transgress the rules and parameters of the traditional documentary practice, granting the imagination with all its artistic potentiality free reign.8 During the period of the French New Wave (1959-68), philosopher film-makers such as Jean-Luc Godard, 
Agnes Varda and Alain Resnais distinguished themselves with their 'interrogations of a world of images - and [...] the power of the moving image itself - characteristically set to literate voiceovers of wilful indeterminacy. ${ }^{9}$ The format continued to gain momentum and distinction amongst philosopher film-makers such as Chris Marker whose meditations on time, humanity and memory in La Jetée (1962) and Sans soleil (1982) are considered by academics and critics to be some of the greatest film essays (or, more accurately given their meditation on the nature of film itself, essay films) of all time. Indeed, the potential for cinema to become a vehicle for ideas about art and imagery, and about the world itself, has been acknowledged since at least as far back as the uber-film theorist André Bazin of the 1940s whose ontological approach to the image was part of an even older quest to 'secure the autonomy of film as both medium and art' that extends back almost as far as the birth of cinema itself. ${ }^{10}$

So, what is a video essay and how does it work as example of Practice as Research in terms of approach, genre and output that might be regarded as a viable alternative to the academic book? A substantial video essay, through both its content and its formal qualities, should of course provide new insights, whether into specific films or sets or films and/or into the aesthetic, socio-economic, political and/or cultural contexts within which those exist. The best of these might also break new ground in demonstrating how the emerging form of the video essay, often articulated as experimental documentary, without voice-over or subtitling, might help us to view the world from a fresh perspective. They should also, as Erlend Lavik argues, demonstrate 'the ability to not just engage with complex thought, but to pull it into focus, and to articulate and communicate those ideas clearly'. serve as 'a springboard to launch into a vital investigation of knowledge, art and culture in the 21st century, including the question of what role cinema itself might play in this critical project: articulating discontent with its own place in the world.' ${ }^{12}$ The video essay format, which can vary considerably in length, has experienced a noticeable renaissance thanks to the work of respected theorist-practitioner-activists such as Catherine Grant and Michael Chanan, amongst others, who not only develop and distribute - mainly through peer-reviewed Open Access platforms - their own new insights through video-essay collections, but also champion the work of others in the field. ${ }^{13}$ Indeed, for Grant, ${ }^{14}$ the potential of the video essay is that it 'can inspire compelling work not 
only because, with its possibilities for direct audiovisual quotation, it can enhance the kinds of explanatory research that have always been carried out on films, but also precisely because of its potential for more "poetic", creative and performative critical approaches to moving image research'.

Of course there will continue to be arguments put forward about the difficulties for the storage, conservation, referencing and archiving of such practice-led research outputs, as well as about equivalence with traditional outputs. The ephemerality and instability of such work, especially when dealing with performance or time-based multi-media installation, for example, 'pose particular challenges to the notion of a fixed, measurable and recordable knowledge. ${ }^{15}$ Nevertheless, the challenge must be taken on if we are to embrace the creative and epistemological potential of twenty-first-century technology; for, "[i]n the age of the digital, there is [surely] no need to stop, or even start, at the printed word any more. ${ }^{16}$ Let's hope that the main networks supporting the media subjects in the UK, MECCSA and BAFTSS will show leadership in this regard and support initiatives and opportunities for innovative routes to publication. ${ }^{17}$

\section{Notes}

1 Practice as Research is also known as Practice-led research and/or as Artistic research. These terms are not exactly interchangeable but are perhaps joined in that they share the overarching mission of the 'production of knowledge or philosophy in action'. See E. Barrett and B. Bolt (eds) (2007) Practice as Research: Approaches to Creative Arts Enquiry (London: I.B. Tauris), p. 5, where creative practice is situated within broader theoretical and research paradigms.

2 For useful bibliographies on this topic, see the references section in the edited collections by Nelson and Barret and Bolt. Most of the texts focus on performance and fine arts, and while many of the concepts, problems and approaches are transferable to media, I would argue that there is more work to be done on understanding the role of media industry professional practice in the academic research agenda.

3 R. Nelson (ed.) (2013) Practice as Research in the Arts: Principles, Protocols, Pedagogies, Resistances (Basingstoke: Palgrave Macmillan), p. 8.

4 HEFCE (2015) 'Expert Panels', http://www.ref.ac.uk/panels/, accessed 4 August 2015. 
5 The chair of the main panel D, Professor Bruce Brown, is an inspirational proponent for PaR. However, sub-panel 36 included only traditional media theorists, archivists, librarians, former journalists, specialists in applied theory such as digital economy, creative industries and cultural tourism, and interdisciplinary work between arts, technology and the social sciences; no one engaged in the articulation and production of Practice as Research.

6 Nelson, Practice as Research in the Arts, p. 4.

7 G. Sullivan (2009) Art Practice as Research: Inquiry in Visual Arts, 2nd edn (London: Sage), p. xx.

8 H. Richter (1992) 'The Film Essay: A New Form of Documentary Film', in Christa Blümlinger and Constatin Wuldd (eds), Schreiben Bilder Sprechen: Texte zum essayistischen Film (Wien: Sonderzahl), pp. 195-98. Translation by Richard Langston.

9 K. B. Lee (2014) 'Video Essay: The Essay Film - Some Thoughts of Discontent', Sight and Sound, http://www.bfi.org.uk/news-opinion/sightsound-magazine/features/deep-focus/video-essay-essay-film-some-thoughts, accessed 15 August 2015.

10 A. Tracy et al. (2013) 'The Essay Film', Sight and Sound, http://www.bfi.org. uk/news-opinion/sight-sound-magazine/features/deep-focus/essay-film, accessed 15 August 2015.

11 E. Lavik (2012) 'The Video Essay: The Future of Academic Film and Television Criticism?' Frames \#1 http://framescinemajournal.com/article/ the-video-essay-the-future/, accessed 17 August 2015.

12 Lee, 'Video Essay'.

13 Catherine Grant, for example, curates AUDIOVISUALCY: Videographic Film and Moving Image Studies, an online forum for video essays about films and moving image texts, film and moving image studies, and film theory: https://vimeo.com/groups/audiovisualcy. Another of Grant's projects is The Audiovisual Essay: Practice and Theory in Videographic Film and Moving Image Studies, intended to encourage further discussion and practice of this form.

14 C. Grant (2013) 'Déjà-Viewing? Videographic Experiments in Intertextual Film Studies', Mediascape (Winter), http://www.tft.ucla.edu/mediascape/ Winter2013_DejaViewing.html, accessed 21 August 2015.

15 Nelson, Practice as Research in the Arts, p. 17.

16 J. Bresland (2010) 'On the Origin of the Video Essay', TriQuarterly 9(1), http://www.northwestern.edu/newscenter/stories/2013/o7/the-video-essaycelebrating-an-exciting-new-literary-form.html\#sthash.BpuwQbrG.dpuf, accessed 15 August 2015.

17 The MeCCSA Practice Network champions practice within the Media Communications and Cultural Studies Association, ensuring that those that 
teach and research practice have a strong voice within the subject association and beyond. BAFTSS (the British Association for Film, TV and Screen Studies) has just launched the first Practice Research Award, reflecting the growing 'performative' tendency of film and moving-image research taking place in/through/around practice-based outputs.

(c) (i) Except where otherwise noted, this work is licensed under a a copy of this license, visit https://creativecommons.org/version4 